\title{
CONSUMO SUSTENTÁVEL E O COMPORTAMENTO DE UNIVERSITÁRIOS: discurso e práxis!
}

\section{1- Giancarlo Gomes*}

Doutorando em Ciências Contábeis e Administração pela Universidade Regional de Blumenau (FURB), Brasil. Professor do curso de Administração da Faculdade de Ciências Integradas do Pontal da Universidade Federal de Uberlândia (FACIP/UFU), Brasil. giancarlo@pzo.com.br

http://lattes.cnpq.br/4556968403215471

\section{2- Patrícia Monteiro Gorni}

Mestre em Administração pela Universidade Regional de Blumenau (FURB), Brasil.

Professora do curso de Administração da Faculdade do Litoral Catarinense (FLC/SOCIESC) e Faculdade Ação de Rio do Sul, Brasil.

patriciagorni@brturbo.com.br

http://lattes.cnpq.br/0516975227230454

\section{3- Marialva Tomio Dreher}

Doutora em Engenharia de Produção pela Universidade Federal de Santa Catarina (UFSC), Brasil. Pós-doutorado em Administração pela Universidade Federal do Rio Grande do Sul (EA/UFRGS), Brasil.

Professora do Programa de Mestrado em Administração e Doutorado em Ciências Contábeis e Administração da Universidade Regional de Blumenau (FURB), Brasil.

marialva@furb.br

http://lattes.cnpq.br/7632895610689620 


\title{
CONSUMO SUSTENTÁVEL E O COMPORTAMENTO DE UNIVERSITÁRIOS: DISCURSO E PRÁXIS!
}

\section{RESUMO}

O estudo tem por objetivo analisar o comportamento, discurso e prática, dos jovens universitários sobre o consumo sustentável. O método adotado foi a pesquisa quantitativa e de levantamento, realizada em uma universidade na cidade de Blumenau, SC. A população pesquisada foi composta por 330 estudantes. Os resultados apontam que, a maioria dos universitários pesquisados demonstra estar consciente do seu papel em relação aos cuidados com o meio ambiente. Apesar de esse fato representar um posicionamento favorável ao consumo sustentável, ele revela apenas a consciência dos respondentes sobre as problemáticas ambientais. O discurso dos universitários permite depreender uma preocupação com a conservação ambiental no momento de decisão do consumo. A prática desses universitários revela uma realidade diferente, em especial no que tange à valorização da relação custo-benefício em detrimento da relação custo-conservação ambiental e/ou contribuição pessoal com a aquisição de produtos e embalagens menos nocivos ao ambiente. A pouca cultura de conscientização enraizada na sociedade e o alto custo dos produtos ecológicos em comparação aos demais produtos tradicionais em oferta no mercado devem ser considerados. Para uma geração de poucos recursos, essa situação pode ser resultado da falta de alternativa econômica para participar ativamente dos movimentos em prol do consumo sustentável.

\section{Palavras-Chave}

Comportamento do consumidor; consumo sustentável; universitários.

\section{SUSTAINABLE CONSUMPTION AND BEHAVIOR OF COLLEGE: DISCOURSE AND PRACTICE!}

\begin{abstract}
The study aims to analyze the behavior, speech and practice of university students about sustainable consumption. The method used was quantitative research and survey, conducted in a university in the city of Blumenau, SC. The research population consisted of 330 students. The results show that most university students surveyed show be aware of their role in relation to the care of the environment. Although it can represent a stand for sustainable consumption, it reveals only the respondents' awareness on environmental issues. The discourse of the university enables us to conclude a concern for environmental conservation at the time of consumption decision. The practice of these students reveals a different reality, especially in regard to recovery of cost-benefit at the expense of environmental conservation cost and/or personal contribution to the acquisition of products and packaging less harmful to the environment. A little culture awareness rooted in society and the high cost of green products compared to other traditional products on offer in the market must be considered. For a generation of modest means, this could be the result of a lack of economic alternative to actively participate in the movement towards sustainable consumption.
\end{abstract}

\section{Keywords}

Consumer behavior; sustainable consumption; university. 


\section{Introdução}

A sociedade vem sentindo, ao longo dos últimos anos, o efeito de várias mudanças ecológicas, tais como as mudanças climáticas, que resultam em tragédias em todos os cantos do mundo. Esse cenário promove um repensar sobre o comportamento humano na sua relação com o ambiente. Conforme Gomes (2006), o crescente processo de industrialização sempre foi bem aceito pela sociedade, uma vez que o progresso econômico sempre foi buscado incessantemente. No entanto, os recursos naturais são utilizados como se fossem infinitos, não havendo qualquer preocupação com os impactos das atividades realizadas.

Um dos pilares que sustentam o desenfreado processo de industrialização é o consumo inadequado, aquele que extrapola o limite, o sentido de "necessidade", para vários outros campos, e que tem constituído objeto de pesquisa da sociologia e da psicologia no estudo do comportamento humano e sua relação social. Neste sentido, Schultz (2002) ressalta que se os atuais padrões de consumo praticados pelos países desenvolvidos forem mantidos e seguidos por outros países, a capacidade do planeta sustentar tudo isso, por meio de recursos naturais, estará seriamente comprometida, e, em poucos anos, muitos dos recursos naturais hoje disponíveis irão desaparecer.

Emergem também movimentos contrários a essa tendência. Na visão de Scarpinelli e Ragassi (2003), a preocupação emergente com questões ambientais deve-se ao aumento dos problemas ecológicos, degradação do meio ambiente, visão individualista das empresas e, por fim, à pressão da educação ambiental, que hoje, veem dando grande ênfase a ações relativamente importantes para a conscientização ambiental.

De acordo com Sutherland e Thompson (2003), a juventude está associada ao consumismo e ao materialismo, vinculados às marcas e às tecnologias, com as quais se identificam, afirmam-se e se diferenciam perante seus pares e demais referentes sociais, criando um estilo de vida que cultiva o presente, o efêmero e a satisfação de todas as suas necessidades. No entanto, conforme Cardoso e Cairrão (2007), é crescente, também, o número de jovens que vêm apresentando sinais de independência e de maturidade, comportamentos que revelam a busca da afirmação da sua personalidade, a partir da qual passam a ter consciência ecológica e ambiental, ligada à preservação da vida e das condições de coexistência da humanidade com a natureza, ainda que, por vezes, notem-se discrepâncias entre essa consciência e a prática.

Entretanto, o conhecimento das questões ambientais, apesar de ser considerado como um indicador da possibilidade de ação consciente do consumidor, não parece significar obrigatoriamente um comportamento de compra ecologicamente correto. Perante esta complexidade surge o seguinte problema que esta investigação pretender responder: Qual é o comportamento dos jovens universitários quanto ao consumo sustentável?

No intuito de entender melhor tal contexto, este estudo tem por objetivo analisar o comportamento, discurso e prática dos jovens universitários no que se refere ao consumo sustentável, partindo do pressuposto que a população pesquisada possui acesso à disseminação de conhecimentos que podem favorecer um comportamento mais adequado quanto ao consumo sustentável.

\section{Aporte Teórico}

Conhecer as características do consumidor é vital para qualquer estratégia assumida em direção ao consumo sustentável. No entanto, isso não é algo simples, pois o comportamento humano é complexo, sendo influenciado pelo modo de vida do indivíduos, pelas estruturas sociais, pelos valores da sociedade, pela cultura, pelos valores e crenças pessoais, entre outros. Diante dessa complexidade, o estudo do comportamento do consumidor envolve várias áreas do conhecimento, principalmente as ciências sociais e a psicologia (CAPELINI, 2007).

De acordo com Gade (2000), o comportamento do consumidor se trata de uma atividade física, mental e emocional obtida na seleção, compra e uso de produtos e serviços para satisfação de necessidades e desejos. Neste mesmo sentido, para Mittal e Newman (2001), o comportamento do consumidor pode ser definido como as atividades físicas e mentais realizadas por clientes de bens de consumo e industriais, que resultam em decisões e ações como, comprar e utilizar produtos e serviços, bem como pagar por eles.

Para Solomon (2002), o comportamento do consumidor compreende o estudo dos processos envolvidos quando indivíduos ou grupos selecionam, compram, usam ou dispõem de produtos, serviços e idéias, ou experiências, para satisfazer necessidades e desejos. Corroborando com esta definição, conforme Minor e 
Mowen (2003), o comportamento do consumidor é o estudo das unidades compradoras e dos processos de troca envolvidos na aquisição, no consumo e na disposição de mercadorias, serviços, experiências e idéias.

Engel, Blackwell e Miniard (2000) agruparam os fatores e determinantes que influenciam a tomada de decisão do consumidor em três categorias, sendo elas: (1) diferenças individuais (recursos do consumidor, conhecimento, atitudes, motivação, personalidade, valores e estilo de vida); (2) influências ambientais (cultura, classe social, influência pessoal, família e situação); e (3) processos psicológicos (informação em processamento, aprendizagem e mudança de atitude e comportamento).

Em meio à complexidade que envolve o comportamento do consumidor, destaca-se a importância da sua relação com o meio ambiente. Conforme Portilho (2005), durante a organização para a Rio 92, as negociações preliminares envolveram controvertidos debates acerca da relação entre estilo de vida, práticas de consumo e problemas ambientais globais. Os documentos produzidos durante a conferência, especialmente a Agenda 21, a Declaração do Rio e o Tratado das ONGs, apontaram a responsabilidade dos estilos de vida e consumo em relação à crise ambiental.

Nesse contexto, surge a reflexão sobre como os indivíduos podem suprir sua necessidade de consumir bens e serviços, de modo a não promover a degradação ambiental, pois, mesmo o consumo de poucas pessoas, ao longo de suas vidas, faz diferença, tendo impacto sobre a sociedade e o meio ambiente. Kotler (2000) argumenta que o comportamento de consumo desvinculado da preservação ambiental tende a submeter às gerações futuras a um ônus econômico e social intolerável, resultante do esgotamento de recursos e da poluição decorrente do uso indiscriminado de produtos provocadores de deterioração do meio ambiente.

Nessa realidade, desponta o consumidor consciente, que, de acordo com Mourão (2010), preocupa-se com o impacto da produção e do consumo sobre o meio ambiente, buscando a melhor relação entre preço, qualidade e atitude social em produtos e serviços oferecidos no mercado, além de mobilizar outros consumidores para a prática do consumo consciente. Consumir com consciência é uma questão de cidadania, pois o consumo de um grande número de pessoas, mesmo por um período curto de tempo, causa impacto (COLTRO, 2006). Fraj e Martinez (2006) argumentam que o comportamento do consumidor consciente dos problemas ambientais tem sido analisado não somente por meio da conduta de compra, reciclagem ou eliminação do produto, mas também através da observação de atitudes ativas e positivas, que refletem o posicionamento do consumidor ecológico consciente.

Conforme o Instituto Akatu (2010), o consumidor consciente busca o equilíbrio entre a sua satisfação pessoal e a sustentabilidade do planeta, lembrando que a sustentabilidade implica um modelo ambientalmente correto, socialmente justo e economicamente viável. Esse consumidor reflete a respeito de seus atos de consumo e sobre como eles irão repercutir não só sobre si mesmo, mas também sobre as relações sociais, a economia e a natureza. O consumidor consciente também busca disseminar o conceito e a prática do consumo consciente, fazendo com que pequenos gestos de consumo realizados por um número muito grande de pessoas promovam grandes transformações.

No ano de 2006, o Instituto Akatu realizou uma pesquisa com 1.275 adultos de todas as classes sociais, residentes nas 11 principais cidades das cinco regiões geográficas do País (Norte, Nordeste, Sudeste, Centro-Oeste e Sul), que revela o estágio em que se encontra o consumidor brasileiro em relação ao consumo consciente. Dentre os resultados obtidos, verificou-se que existe uma perceptível distância entre o falar (valor) e o agir (comportamento). A assimilação dos valores pela maioria dos consumidores aconteceu na maior parte das questões exploradas na pesquisa. Já em relação aos "comportamentos", essa assimilação ocorreu somente na minoria das situações propostas. Isto denota que torna-se necessário transformar "valores" já assimilados em “comportamentos" efetivos (INSTITUTO AKATU, 2010).

Conforme Klineberg, McKeever e Rothenbach (1998) é possível mensurar o nível de consciência ambiental de uma pessoa de quatro formas. O modo mais comum consiste em fornecer opções entre proteção ambiental e interesses políticos e econômicos futuros, tais como, aumento na taxa de emprego e crescimento econômico. A segunda forma é promover questionamentos a respeito da percepção dos indivíduos sobre a poluição ambiental. Outra maneira é identificar se os respondentes, de alguma forma, estão envolvidos em alguma atividade em prol do meio ambiente. E a quarta maneira é fazer perguntas sobre danos globais ao meio ambiente. Neste contexto, Calomarde (2000, p.30) desenvolveu formas para facilitar a caracterização ecológica dos consumidores diferenciando-os conforme suas atitudes e segmentando-os a partir das seguintes questões: 
Consciência ecológica: representa o componente de crenças e conhecimentos ecológicos. É a composição cognitiva da atitude e está intimamente ligada ao nível de informação recebida e recordada, aumenta por meio da recordação e da informação que se faz chegar ao consumidor sobre os produtos e marcas ecológicas, especialmente mediante a tangibilização dos benefícios, os conhecimentos e as crenças ecológicas que o consumidor mantém.

Ecopostura: É a dimensão afetiva de preferência para os produtos ecológicos. Sua intensidade se vê modulada pela cultura do grupo social ao qual pertence ou aspira pertencer, pela educação recebida e pela informação recebida, fundamentalmente. Quanto mais positiva seja esta atitude, mediante o estímulo ou pertencimento a um determinado grupo social, maior será a ponderação dos benefícios ecológicos no conjunto de benefícios atribuídos ao produto ou marca na avaliação.

Ecoatividade: é a tendência a atuar ecologicamente. Reside fundamentalmente na personalidade do indivíduo. Saber estimá-la é também tarefa do marketing ambiental, como saber reconhecer até onde se pode esperar resposta de cada grupo de consumidores com cada tipo de produto-mercado.

Outras maneiras de designar o consumo com vistas à preocupação com o meio ambiente é consumo sustentável e consumo verde. Para Hansen e Schrader (1997), o consumo sustentável é o consumo de bens e serviços com o devido respeito aos recursos ambientais. Este consumo se dá de maneira que garanta o atendimento das necessidades das gerações atuais sem danificar o atendimento das necessidades das gerações futuras. Como salienta Portilho (2005), as ações e as escolhas individuais motivadas por preocupações ambientais passaram a ser vistas como essenciais, e o consumidor como o responsável, por meio de suas demandas e escolhas cotidianas, por mudanças nas matrizes energéticas e tecnológicas do sistema de produção.

O consumo sustentável implica necessariamente, redução de consumo. Desta forma, consumo sustentável não é uma quantidade específica entre o baixo consumo causado pela pobreza e o alto consumo gerado pela riqueza, mas um padrão de consumo bem diferente para todos os níveis de renda pessoal em países do mundo todo (GONÇALVES-DIAS, MOURA, 2007). Já na visão de Capelini (2007), o consumo sustentável abrange muito mais do que a escolha de produtos dentre os mais sustentáveis. Exige a discussão ampla da revisão do modelo de consumo vigente e, em alguns casos, o consumo sustentável pode levar a um não consumo.

Paavola (2001) descreve o consumo sustentável com o tipo de consumo que envolve redução de impactos ambientais adversos. Esse é ainda um termo abrangente, que traz uma série de fatores-chave, tais como: o aumento do uso de fontes de energias renováveis, a minimização da produção de lixo, a adoção de uma perspectiva de ciclo de vida que leve em conta a dimensão equitativa etc. Neste sentido, os produtos ecologicamente corretos dependem das novas preferências dos consumidores por produtos verdes, pois a maior consciência ecológica vem concorrendo para uma remodelação do conceito de qualidade do produto, que agora precisa ser ecologicamente correto (AMORIM, et al, 2009).

Em relação ao consumo sustentável, destacam-se as embalagens como importantes aspectos na geração de resíduos. Assim, para que determinado produto possa ser considerado como ambientalmente correto, não só o produto em si não deve ser prejudicial ao maio ambiente, mas também a sua embalagem (BEDANTE, 2004). Schwepker, Jr. e Cornwell (1991) apontam que os consumidores estão dispostos a adquirir produtos em embalagens maiores com menor frequência e também produtos em embalagens menos atrativas para eliminar excessos desnecessários, bem como produtos condicionados em embalagens redesenhadas com o intuito de minimizar o impacto no meio ambiente em função da quantidade de resíduos sólidos a serem descartados.

Segundo Capelini (2007), o que diferencia consumo sustentável de consumo verde é a escolha do produto a ser comprado e não a necessidade de adquirir determinado produto. No consumo verde, o foco está na inovação tecnológica, relativa a produtos que agreguem qualidade ambiental. Essa abordagem, sozinha, tem inegáveis benefícios ambientais, contudo, tem como limitações a redução da escolha entre um produto e outro, uma marca e outra, o que não se refere a consumismo e não-consumismo; refere-se ao esverdeamento do consumo; tem foco concentrado em uma classe de consumidores. Conforme Portilho (2005), o consumidor verde não consome menos, mas de maneira diferenciada. Deixa de enfocar aspectos como a descartabilidade, a obsolescência planejada e a redução do consumo. Contudo, enfatiza a reciclagem, o uso de tecnologias limpas, a redução do desperdício e o incremento de um mercado consumidor verde. 
Reconhecidos os limites e armadilhas da estratégia de consumo verde, surgiram propostas que cada vez mais enfatizam as ações coletivas e as mudanças políticas e institucionais (mais do que as tecnológicas, econômicas e comportamentais), como a proposta de consumo sustentável. Por conseguinte, a alternativa para as ações individuais seria estabelecer um compromisso com a moralidade pública, por meio de ações coletivas, e implementar políticas multilaterais de regulação, tanto da produção, quanto do consumo. A estratégia de produção e consumo limpos ou verdes começa a perder espaço para uma estratégia de produção e consumo sustentáveis (PORTILHO, 2005).

\section{Metodologia da Pesquisa}

Na sua abordagem, esta pesquisa é quantitativa. Conforme Richardson (1989) este método, como o próprio nome indica, caracteriza-se pelo emprego da quantificação tanto nas modalidades de coleta de informações, quanto no tratamento dessas, através de técnicas estatísticas, desde as mais simples, como percentual, média, desvio-padrão, às mais complexas, como coeficiente de correlação, análise de regressão, etc. Com relação aos procedimentos, esta pesquisa se caracteriza como de levantamento ou survey, que, segundo Creswell (2010) a pesquisa de levantamento proporciona uma descrição quantitativa ou numérica de tendências, de atitudes ou de opiniões de uma população, estudando uma amostra dessa população. Abrange estudos transversais e longitudinais, utilizando questionários ou entrevistas estruturadas para a coleta de dados, com a intenção de generalizar a partir de uma amostra para uma população.

A pesquisa foi realizada em uma universidade de Blumenau, SC. A população foi composta por 330 estudantes da área de Ciências Sociais Aplicadas do curso de Administração, de um total de 1.413 alunos deste curso. A margem de erro e o nível de confiança foi de 95\%. Essa população estuda em uma universidade de âmbito regional e caráter comunitário, porém com cobrança de mensalidades, representando um público de estudantes que, em sua maioria, trabalha nas empresas da região para custear suas despesas com a formação acadêmica. Isto evidencia que a maioria também já possui remuneração e, em alguma medida, experiência com a administração pessoal do consumo.

Quanto ao procedimento de coleta de dados, utilizou-se a aplicação de questionário, baseado no estudo de Cardoso e Cairrão (2007), que desenvolveram um estudo na mesma temática nas cidades de Porto e Coimbra em Portugal com 330 universitários. Este estudo foi baseado em três hipóteses:

H1: O nível de consciência ambiental dos jovens universitários tem um impacto positivo na sua atitude em relação ao consumo sustentável;

H2: Atitudes positivas em relação ao consumo sustentável têm um impacto positivo na intenção de compra de produtos ecológicos;

H3: O nível de consciência ambiental dos jovens universitários tem um impacto positivo na intenção de compra de produtos ecológicos.

Na construção do questionário, os autores fundamentaram-se em escalas já testadas e desenvolvidas por outros pesquisadores. Para avaliar o grau de consciência ambiental dos pesquisado, foi utilizada a escala Environmental Concern (EC) proposta por Straughan e Roberts (1999), utilizada por Bedante (2004) e por Cardoso e Cairrão (2007). A avaliação das atitudes dos pesquisados frente ao consumo sustentável, foi feita com base na escala Ecologically Conscious Consumer Behavior (ECCB), já utilizada por Lages e Neto (2002). Após a coleta, organização e classificação, os dados foram interpretados para que pudessem responder aos questionamentos e objetivos desta investigação.

\section{Comportamento, Discurso e Prática, dos Jovens Universitários sobre o Consumo Sustentável}

Nesta etapa são analisados os dados obtidos com a pesquisa sobre o comportamento dos universitários em relação ao consumo sustentável. A análise está dividida em três tópicos, a saber: Consciência Ambiental; Intenção de Compra de Produtos Ecológicos e Consumo Sustentável. O questionário foi elaborado com base no modelo da escala Likert e as respostas obtidas estão representadas por meio de tabelas, com as seguintes atribuições: número 1 para Discordo Totalmente; número 2 para Discordo; número 3 para Neutro; número 4 para Concordo e número 5 para Concordo Totalmente. Nas tabelas são 
apresentados os números de frequência absoluta (F) e frequência relativa (\%). Quanto ao Teste de Cronbach (confiabilidade da escala), nas questões da Tabela 1, Tabela 2 e Tabela 3 (alpha $=0,86$ ), este valor de escala é confiável, se considerar-se aceitável valores de alfa acima de 0.60.

Com relação ao perfil dos estudantes universitários questionados, observou-se que a idade média é de 22,5 anos, sendo que o mais novo tinha 16 anos, e o mais velho, 47 anos; a mediana foi de 21 anos, caracterizando a população desta pesquisa como sendo composta de jovens estudantes universitários. Quanto ao gênero, $52,7 \%$ são do sexo feminino e $47,3 \%$ do sexo masculino, este equilíbrio facilita a análise.

\subsection{Consciência Ambiental}

A primeira parte do questionário versava sobre a consciência ambiental e continha 12 perguntas, evidenciadas nas tabelas 1 e 2 . A tabela 1 apresenta afirmativas que não consideram a fragilidade ambiental e, a tabela 2, ao contrário, refere-se a frases que relatam os problemas com o meio ambiente.

Tabela 1 - Consciência Ambiental - parte 1

\begin{tabular}{|c|c|c|c|c|c|c|c|c|c|c|}
\hline \multirow{2}{*}{ ITENS DA ESCALA } & \multicolumn{2}{|c|}{1} & \multicolumn{2}{|c|}{2} & \multicolumn{2}{|c|}{3} & \multicolumn{2}{|r|}{4} & \multicolumn{2}{|c|}{5} \\
\hline & F. & $\%$ & F. & $\%$ & F. & $\%$ & F. & $\%$ & F. & $\%$ \\
\hline $\begin{array}{l}\text { As plantas e os animais existem, basicamente, para serem util } \\
\text { pelos seres humanos. }\end{array}$ & 144 & 44 & 120 & 36 & 32 & 10 & 27 & 8 & 7 & 2 \\
\hline A humanidade foi criada para dominar a natureza. & 142 & 43 & 126 & 38 & 30 & 9 & 22 & 7 & 9 & 3 \\
\hline $\begin{array}{l}\text { Os seres humanos têm o direito de modificar o meio ambiente para } \\
\text { ajustá-lo as suas necessidades. }\end{array}$ & 95 & 29 & 112 & 34 & 70 & 21 & 39 & 12 & 14 & 4 \\
\hline $\begin{array}{l}\text { Os seres humanos não precisam se adaptar ao amb } \\
\text { porque podem adaptar o meio ambiente às suas necess }\end{array}$ & 78 & 24 & 116 & 35 & 76 & 23 & 45 & 14 & 12 & 4 \\
\hline
\end{tabular}

Na Tabela 1, as duas primeiras questões obtiveram os maiores índices (44\% e $43 \%$ respectivamente) para as alternativas discordo totalmente e discordo. Na primeira questão, que afirma "As plantas e os animais existem, basicamente, para serem utilizados pelos seres humanos", 44\% discordaram totalmente e 36\% discordaram. E, em relação à segunda, em que se afirma que "A humanidade foi criada para dominar a natureza", 43\% discordam totalmente e $38 \%$ discordam.

Neste caso, a maioria dos estudantes entende que existe um limite sobre a supremacia do homem em relação à natureza. Isto evidencia que os universitários entrevistados possuem certo entendimento sobre a problemática ambiental.

No entanto, torna-se importante destacar que, apesar de representar a minoria, $8 \%$ dos estudantes concordam com a primeira frase, $2 \%$ concordam totalmente e $10 \%$ se mantiveram indiferentes. Já em relação à segunda frase, $7 \%$ concordam e 3\% concordam totalmente e $9 \%$ se mantiveram indiferentes.

Observa-se que, apesar da maioria desses jovens entenderem que os indivíduos precisam respeitar as fragilidades do meio ambiente, este pensamento ainda não representa a totalidade. Sobre isto, recorre-se ao que Calomarde (2000, p. 30) propõe sobre a consciência ecológica dos consumidores, quando aponta que essa representa o componente de crenças e conhecimentos ecológicos e que a composição cognitiva da atitude está fortemente atrelada ao nível de informação recebida por essas pessoas.

As duas últimas frases da tabela 1 também apresentaram resultados favoráveis à consciência ambiental por parte dos respondentes. São frases parecidas, que tratam da modificação do meio ambiente pelo homem em virtude de suas necessidades, e, em virtude disso, correspondem a resultados semelhantes. Em relação à afirmativa, "Os seres humanos têm o direito de modificar o meio ambiente para ajustá-lo as suas necessidades", $29 \%$ discordaram totalmente e $34 \%$ discordaram. Esse resultado aponta um aspecto relevante quanto à consciência ambiental. A última frase pontua que "Os seres humanos não precisam se adaptar ao ambiente natural, porque podem adaptar o meio ambiente às suas necessidades". Neste caso, $24 \%$ discordaram totalmente, 35\% discordaram e $23 \%$ mantiveram-se indiferentes.

Nestas duas questões, chama atenção o número de pessoas que se mantiveram indiferentes, que foi de $21 \%$ e $23 \%$ respectivamente. Este cenário pode estar relacionado ao fato de que, em dadas circunstâncias, os seres humanos precisam adequar as condições ambientais para a sua sobrevivência, como, por 
exemplo, o cultivo de alimentos. Ambas as questões não deixam claro até que ponto os indivíduos poderiam adaptar o meio ambiente às suas necessidades.

Tabela 2 - Consciência Ambiental - parte 2

\begin{tabular}{|c|c|c|c|c|c|c|c|c|c|c|}
\hline \multirow{2}{*}{ ITENS DA ESCALA } & \multicolumn{2}{|c|}{1} & \multicolumn{2}{|c|}{2} & \multicolumn{2}{|c|}{3} & \multicolumn{2}{|r|}{4} & \multicolumn{2}{|c|}{5} \\
\hline & $\mathrm{F}$. & $\%$ & F. & $\%$ & F. & $\%$ & F. & $\%$ & F. & $\%$ \\
\hline A humanidade está abusando seriamente do meio ambiente. & 3 & 1 & 13 & 4 & 18 & 5 & 108 & 33 & 186 & 56 \\
\hline $\begin{array}{l}\text { Os seres humanos devem viver em harmonia com a natureza para } \\
\text { que possam sobreviver melhor. }\end{array}$ & 2 & 1 & 6 & 2 & 17 & 5 & 126 & 38 & 179 & 54 \\
\hline $\begin{array}{l}\text { Quando os seres humanos interferem na natureza, isso } \\
\text { freqüentemente produz conseqüências desastrosas. }\end{array}$ & 3 & 1 & 11 & 3 & 30 & 9 & 141 & 43 & 144 & 44 \\
\hline $\begin{array}{l}\text { O planeta Terra é como uma aeronave, com espaço e recursos } \\
\text { limitados. }\end{array}$ & 9 & 3 & 19 & 6 & 55 & 17 & 149 & 45 & 98 & 30 \\
\hline O equilíbrio da natureza é muito delic & 3 & 1 & 11 & 3 & 42 & 13 & 175 & 53 & 97 & 29 \\
\hline $\begin{array}{l}\text { Para manter uma economia saudá } \\
\text { para que o crescimento industria }\end{array}$ & 4 & 1 & 17 & 5 & 57 & 17 & 175 & 53 & 76 & 23 \\
\hline $\begin{array}{l}\text { Estamos nos aproximando do número limite de habitantes que a } \\
\text { terra pode suportar. }\end{array}$ & 15 & 5 & 55 & 17 & 83 & 25 & 121 & 37 & 56 & 17 \\
\hline $\begin{array}{l}\text { Existem limites de crescimento para além dos quais a nossa } \\
\text { sociedade industrializada não pode expandir-se. }\end{array}$ & 11 & 3 & 44 & 13 & 111 & 34 & 117 & 35 & 44 & 13 \\
\hline
\end{tabular}

A tabela 2 apresenta frases que refletem algumas preocupações em relação ao meio ambiente. As três primeiras pontuam o modo abusivo com que os seres humanos estão explorando o meio ambiente e que deveriam viver em harmonia com a natureza, apresentando os maiores índices de respostas - concordo totalmente e concordo - desta tabela. As cinco últimas questões abordam a fragilidade da natureza e a capacidade do planeta. A frase "O planeta Terra é como uma aeronave, com espaço e recursos limitados" apresenta $30 \%$ de concordo totalmente e $45 \%$ de concordo; a questão "O equilíbrio da natureza é muito delicado e facilmente perturbado" contou com 29\% de concordo totalmente e $53 \%$ de concordo; e a afirmativa "Para manter uma economia saudável teremos que desenvolvê-la para que o crescimento industrial seja controlado" contou com $23 \%$ de concordo totalmente e $53 \%$ de concordo. Já no que tange às duas últimas questões, que são mais categóricas ao se referir à capacidade de carga do planeta, apesar de a maioria mostrar concordância, destaca-se o número de pessoas que se mantiveram indiferentes que foi de $25 \%$ e $34 \%$ respectivamente (para a penúltima e última questões).

Ressalta-se que as tabelas 1 e 2 demonstram a existência de uma percepção dos estudantes em relação às problemáticas ambientais. É possível constatar que a maioria dos jovens pesquisados possui um nível favorável de consciência ambiental. Contudo, torna-se importante destacar que essas tabelas não apresentam as reais atitudes dos respondentes frente às questões apontadas, mas apenas sua opinião sobre o tema.

\subsection{Intenção de Compra de Produtos Ecológicos}

Neste tópico é analisada a intenção de compra de produtos ecológicos por parte dos universitários pesquisados.

Ao verificar a Tabela 3, percebe-se que, nas compras, o preço sempre é o item mais importante para 30 $\%$ dos universitários pesquisados; $51 \%$ ficaram neutros em relação a esta questão e apenas 15\% responderam que o preço não é o mais importante. As escolhas ocorrem dentro de uma capacidade orçamentária. Essa restrição indica não ser possível contemplar todos os desejos, por isso o indivíduo deve fazer escolhas (STIGLITZ; WALSH, 2003).

O percentual dos universitários pesquisados que priorizam a compra de produtos em embalagens biodegradáveis foi de $16 \%$ para os que concordam e que concordam totalmente, número baixo se considerarmos que $43 \%$ disseram discordar ou discordar totalmente desta afirmativa, outros $40 \%$ mantiveram-se neutros. Este resultado representa um desafio à venda deste tipo de produto. No entanto, $32 \%$ concordam em comprar um produto numa embalagem reciclável em alternativa a comprar um produto similar numa embalagem não reciclável, $16 \%$ concordam totalmente e $37 \%$ foram neutros a 
questão. $45 \%$ dos pesquisados estariam dispostos a comprar alguns produtos (que agora compram em embalagens menores) em embalagens maiores e com menor frequência, respondendo que concordam e que concordam totalmente com a afirmativa. Resta saber se a iniciativa parte da intenção do entrevistado, ou das opções já disponíveis pela preocupação das empresas em atuar nesse campo. Neste sentido, Bedante (2004) aponta que os consumidores estão propensos a consumir mais os produtos contidos em grandes embalagens, pois produtos acondicionados em embalagens maiores levam os consumidores a comprá-los com menos frequência, diminuindo, desta maneira, o consumo de material de embalagem e, consequentemente, seu descarte.

Tabela 3 - Intenção de compra de produtos ecológicos

\begin{tabular}{|c|c|c|c|c|c|c|c|c|c|c|}
\hline \multirow{2}{*}{ ITENS DA ESCALA } & \multicolumn{2}{|c|}{1} & \multicolumn{2}{|c|}{2} & \multicolumn{2}{|c|}{3} & \multicolumn{2}{|c|}{4} & \multicolumn{2}{|c|}{5} \\
\hline & F. & $\%$ & F. & $\%$ & F. & $\%$ & F. & $\%$ & F. & $\%$ \\
\hline Nas suas compras o preço sempre é mais importante & 5 & 2 & 43 & 13 & 167 & 51 & 86 & 26 & 14 & 4 \\
\hline Prioriza compra de produtos em embalagens biodegradáveis. & 42 & 13 & 99 & 30 & 131 & 40 & 41 & 12 & 12 & 4 \\
\hline $\begin{array}{l}\text { Compraria um produto numa embalagem reciclável em alterr } \\
\text { comprar um produto similar numa embalagem não reciclável. }\end{array}$ & 14 & 4 & 34 & 10 & 123 & 37 & 105 & 32 & 52 & 16 \\
\hline $\begin{array}{l}\text { Estaria disposto a comprar alguns produtos (que agora compro em } \\
\text { embalagens menores) em embalagens maiores e com menor freqüência. }\end{array}$ & 11 & 3 & 41 & 12 & 132 & 40 & 104 & 32 & 42 & 13 \\
\hline $\begin{array}{l}\text { Compraria um produto numa embalagem pouco tradicional (por exemplo, } \\
\text { redonda quando a maioria é quadrada) se isso se traduzisse na criação de } \\
\text { menos resíduos sólidos (lixo). }\end{array}$ & 14 & 4 & 25 & 8 & 106 & 32 & 101 & 31 & 84 & 25 \\
\hline $\begin{array}{l}\text { Compraria um produto com uma embalagem menos atrativa se soubesse } \\
\text { que todo o plástico e/ou papel desnecessário nesta embalagem tivesse sido } \\
\text { eliminado. }\end{array}$ & 12 & 4 & 46 & 14 & 88 & 27 & 100 & 30 & 84 & 25 \\
\hline
\end{tabular}

Verificou-se que $56 \%$ dos universitários concordam e concordam totalmente que comprariam um produto numa embalagem pouco tradicional (por exemplo, redonda quando a maioria é quadrada) se isso se traduzisse na criação de menos resíduos sólidos (lixo). Apenas $12 \%$ responderam que discordam e discordam totalmente da questão. $55 \%$ dos universitários entrevistados responderam que concordam e concordam totalmente e que estariam dispostos a comprar alguns produtos (que agora compram em embalagens menores) em embalagens maiores e com menor frequência. Observa-se uma atenção da maioria em relação à produção de lixo em virtude da embalagem. Neste sentido, conforme Mourão (2010), desponta o consumidor consciente, que se preocupa com o impacto da produção e do consumo sobre o meio ambiente, em uma busca não somente por preço e qualidade, mas também como uma atitude social.

O último assunto deste bloco se refere a "comprar um produto com uma embalagem menos atrativa se soubesse que todo o plástico e/ou papel desnecessário nesta embalagem tivesse sido eliminado", verificouse que $55 \%$ dos universitários pesquisados concordam e concordam totalmente e $27 \%$ foram neutros, os demais responderam que discordam ou discordam totalmente da questão. Observa-se um pequeno avanço na questão da consciência sobre o uso de embalagens descartáveis ou menores.

\subsection{Consumo Sustentável}

Com relação ao Consumo Sustentável, constatou-se que a maior parte dos entrevistados manteve-se neutra em suas respostas, conforme demonstra a Tabela 4.

Na Tabela 4, percebe-se que 115 universitários (35\%) responderam concordar com a questão “Quando tenho que escolher entre dois produtos iguais, eu escolho sempre o que é menos prejudicial às outras pessoas e ao meio ambiente"; outros 134, ou 41\% dos respondentes, mostraram-se neutros em relação à pergunta.

Ao serem questionados sobre a compra de produtos fabricados ou vendidos por empresas que prejudicam ou desrespeitam o meio ambiente, $42 \%$ dos universitários se mantiveram neutros, já $21 \%$ responderam que concordam e 16 universitários, 5\% do total, concordam totalmente com a questão. Este resultado evidencia a constatação de que os universitários pesquisados não têm percepção clara a respeito do poder do consumidor na preservação ambiental. 


\begin{tabular}{|c|c|c|c|c|c|c|c|c|c|c|}
\hline \multirow{2}{*}{ ITENS DA ESCALA } & \multicolumn{2}{|c|}{1} & \multicolumn{2}{|c|}{2} & \multicolumn{2}{|c|}{3} & \multicolumn{2}{|c|}{4} & \multicolumn{2}{|c|}{5} \\
\hline & F. & $\%$ & F. & $\%$ & $\mathrm{~F}$. & $\%$ & $\mathrm{~F}$. & $\%$ & F. & $\%$ \\
\hline $\begin{array}{l}\text { Quando tenho que escolher entre dois produtos } \\
\text { iguais, eu escolho sempre o que e menos } \\
\text { prejudicial às outras pessoas e ao meio ambiente. }\end{array}$ & 11 & 3 & 37 & 11 & 134 & 41 & 115 & 35 & 33 & 10 \\
\hline $\begin{array}{l}\text { Não compro produtos fabricados ou vendidos por } \\
\text { empresas que prejudicam ou desrespeitam o meio } \\
\text { ambiente. }\end{array}$ & 13 & 4 & 70 & 21 & 139 & 42 & 91 & 28 & 16 & 5 \\
\hline $\begin{array}{l}\text { Faço sempre um esforço para reduzir o uso de } \\
\text { produtos feitos de recursos naturais escassos. }\end{array}$ & 10 & 3 & 36 & 11 & 126 & 38 & 122 & 37 & 33 & 10 \\
\hline $\begin{array}{l}\text { Quando possível, escolho sempre produtos que } \\
\text { causam menos poluição. }\end{array}$ & 8 & 2 & 23 & 7 & 58 & 18 & 186 & 56 & 55 & 17 \\
\hline $\begin{array}{l}\text { Já convenci amigos e familiares a não comprar } \\
\text { produtos que prejudicam o meio ambiente. }\end{array}$ & 33 & 10 & 67 & 20 & 129 & 39 & 82 & 25 & 15 & 5 \\
\hline $\begin{array}{l}\text { Para a minha casa não compro produtos que } \\
\text { prejudiquem o meio ambiente. }\end{array}$ & 22 & 7 & 62 & 19 & 174 & 53 & 59 & 18 & 10 & 3 \\
\hline $\begin{array}{l}\text { Não compro um produto quando sei dos possíveis } \\
\text { danos que ele pode causar ao meio ambiente. }\end{array}$ & 15 & 5 & 49 & 15 & 108 & 33 & 134 & 41 & 24 & 7 \\
\hline $\begin{array}{l}\text { Não compro produtos e alimentos que possam } \\
\text { causar a extinção de algumas espécies animais ou } \\
\text { vegetais. }\end{array}$ & 16 & 5 & 33 & 10 & 107 & 32 & 130 & 39 & 42 & 13 \\
\hline $\begin{array}{l}\text { Procuro comprar produtos feitos em papel } \\
\text { reciclado. }\end{array}$ & 17 & 5 & 50 & 15 & 125 & 38 & 105 & 32 & 32 & 10 \\
\hline $\begin{array}{l}\text { Sempre que possível, compro produtos feitos de } \\
\text { material reciclado. }\end{array}$ & 19 & 6 & 43 & 13 & 108 & 33 & 121 & 37 & 38 & 12 \\
\hline $\begin{array}{l}\text { Tento comprar apenas produtos que possam ser } \\
\text { reciclados. }\end{array}$ & 16 & 5 & 65 & 20 & 141 & 43 & 85 & 26 & 22 & 7 \\
\hline $\begin{array}{l}\begin{array}{l}\text { Evito comprar produtos que não sejam } \\
\text { biodegradáveis. }\end{array} \\
\end{array}$ & 18 & 5 & 70 & 21 & 165 & 50 & 62 & 19 & 15 & 5 \\
\hline $\begin{array}{l}\text { Compro produtos naturais porque são mais } \\
\text { saudáveis. }\end{array}$ & 9 & 3 & 30 & 9 & 90 & 27 & 139 & 42 & 61 & 18 \\
\hline $\begin{array}{l}\text { Prefiro alimentos sem fertilizantes químicos porque } \\
\text { respeitam o meio ambiente. }\end{array}$ & 9 & 3 & 33 & 10 & 121 & 37 & 110 & 33 & 53 & 16 \\
\hline $\begin{array}{l}\text { Estou disposto a pagar um pouco mais por produtos } \\
\text { e alimentos que estejam livres de elementos } \\
\text { químicos que prejudiquem o meio ambiente. }\end{array}$ & 13 & 4 & 54 & 16 & 102 & 31 & 103 & 31 & 55 & 17 \\
\hline $\begin{array}{l}\text { Quando compro produtos e alimentos, a } \\
\text { preocupação com o meio ambiente influencia a } \\
\text { minha decisão de escolha. }\end{array}$ & 20 & 6 & 71 & 22 & 133 & 40 & 85 & 26 & 21 & 6 \\
\hline
\end{tabular}
minha decisão de escolha.

\section{Tabela 4 - Consumo sustentável}

Verificou-se também um percentual elevado de neutralidade em relação ao esforço para reduzir o uso de produtos feitos de recursos naturais escassos, 38\% dos entrevistados permaneceram neutros a esse respeito, enquanto outros 37\% concordam e 10\% concordaram totalmente. Quanto à compra de produtos que causam menos poluição, $56 \%$ universitários concordam e $17 \%$ concordam totalmente em adquirir esse tipo de produto.

Percebeu-se que os universitários já convenceram amigos ou parentes a não comprar produtos que prejudiquem o meio ambiente, os resultados foram: $35 \%$ concordam ou concordam totalmente e $39 \%$ nem concordam, nem discordam. Conforme Mourão (2010), uma das características do consumidor consciente é a mobilização de outros consumidores para a prática do consumo consciente. No entanto, os entrevistados demonstram baixa preocupação na compra de produtos e alimentos que agridam o meio ambiente, apresentando, na maioria, neutralidade nesse aspecto. Dos universitários, 52\% concordam e concordam totalmente que não compram produtos e alimentos que possam causar a extinção de algumas espécies animais ou vegetais.

Ao serem questionados sobre a compra de produtos feitos de papel reciclado, $42 \%$ concordam e concordam totalmente; $38 \%$ mantiveram-se neutros nesta questão e $20 \%$ discordam e discordam totalmente. Quanto à compra de produtos feitos de papel reciclado, $49 \%$ responderam que sempre que possível praticam isso, já $33 \%$ ficaram neutros sobre o questionamento. Na afirmativa seguinte, os resultados mostram que os universitários não tentam comprar apenas produtos que possam ser reciclados, este número é preocupante, pois $43 \%$ dos entrevistados, um número significativo, mostraram-se neutros a respeito dessa afirmativa. Ao que tudo indica, esse posicionamento está ligado ao elevado custo dos produtos reciclados em relação aos não reciclados.

Os universitários foram questionados se evitam comprar produtos que não sejam biodegradáveis; as respostas mostraram que 50\% mantiveram-se neutros, outros 9\% responderam concordar e $5 \%$ 
responderam que concordam totalmente. Percebe-se assim que as respostas não vêm ao encontro do que preconizou Schwepker, Jr. e Cornwell (1991) na década de 90, quando destacavam que os consumidores estariam dispostos a adquirir produtos em embalagens recicláveis e biodegradáveis em detrimento de produtos similares que não obtivessem tais características.

Verificou-se que $60 \%$ dos universitários pesquisados responderam que concordam e concordam totalmente em "comprar produtos naturais porque são mais saudáveis." Ainda verificou-se que $49 \%$ preferem alimentos sem fertilizantes químicos, porque respeitam o meio ambiente.

Dos universitários pesquisados, $31 \%$ concordam e $17 \%$ concordam totalmente em pagar um pouco mais por um produto ou alimento que esteja livre de elementos químicos que prejudicam o meio ambiente. A este respeito, $16 \%$ discordaram, $4 \%$ discordaram totalmente,e outros $31 \%$ não concordaram nem discordaram. A última questão deste bloco se refere à preocupação com o meio ambiente, ou seja, “Quando compro produtos e alimentos, a preocupação com o meio ambiente influencia a minha decisão de escolha"; $40 \%$ dos respondentes mantiveram-se neutros, outros $28 \%$ dos universitários discordam ou discordam totalmente e $32 \%$ concordaram ou concordaram totalmente.

Comparando os dados das tabelas 1, 2 e 3, que apresentam questões referentes a consciência ambiental, com os dados da tabela 4, que trata da prática de consumo sustentável, verificou-se que o discurso da consciência ambiental ainda é mais forte do que a prática do consumo sustentável. Observouse que a quantidade de pessoas que preferiram se manter neutras em relação aos questionamentos sobre o consumo foi expressiva. Retomando aos autores mencionados na revisão teórica, observa-se que o consumo sustentável implica uma mudança considerável na postura das pessoas. Para Mourão (2007), o consumo sustentável implica necessariamente redução de consumo, não estando relacionado ou baixo consumo causado pela pobreza, mas sim, a um padrão de consumo diferente para todos os níveis de renda pessoal.

\section{Conclusão}

O consumo sustentável tornou-se disciplina fundamental no cotidiano dos discursos e práticas de administração, sendo pesquisado por estudiosos e por empresas socialmente e ecologicamente responsáveis, visto que a sociedade vem se conscientizando do seu papel em relação ao meio ambiente. Diante desse movimento, este estudo teve como objetivo verificar o comportamento dos jovens universitários quanto ao consumo sustentável. Partiu-se do pressupostoo de que esta população de pesquisa possui acesso ou muita aproximação com a disseminação de conhecimentos que podem favorecer um comportamento mais adequado quanto ao consumo sustentável.

Nos resultados observou-se, de um modo geral, que os universitários pesquisados acreditam e afirmam que estão conscientes do seu papel em relação aos cuidados com o meio ambiente. Todavia, algumas vezes, é possível que os jovens tenham respondido em função daquilo que é socialmente aconselhável e aceitável, e não em função daquilo que são efetivamente as suas práticas de consumo. Fato esse verificado em algumas práticas de consumo que não corroboram com a preservação ambiental. Cardoso e Cairrão (2007) consideram como consumidor ecologicamente consciente aquele que tem consciência do impacto dos seus hábitos de consumo no meio ambiente e que se empenha em comprar produtos que não prejudiquem o meio ambiente. As hipóteses avaliadas no conteúdo dos questionários aplicados neste estudo comprovaram que:

Na hipótese H1, o nível de consciência ambiental dos jovens universitários tem um impacto positivo na sua atitude em relação ao consumo sustentável, como observado nas Tabelas 1, 2, em que depreende-se que a maioria dos jovens pesquisados possui um nível favorável de consciência ambiental. Entretanto, é fundamental destacar que estes dados não apresentam as reais atitudes dos respondentes frente às questões apontadas, mas apenas sua opinião sobre o tema.

A hipótese $\mathrm{H} 2$ garante que as atitudes positivas em relação ao consumo sustentável têm um impacto positivo na intenção de compra de produtos ecológicos. Este fato foi verificado na Tabela 3, em que se percebe que os universitários ainda optam por comprar produtos em função do preço. A escassez de recursos é uma realidade para os alunos jovens que trabalham para pagar a universidade, talvez por isso, pode-se concluir que poucos priorizam a compra de produtos em embalagens biodegradáveis. No entanto, mesmo assim, muitos concordam em comprar um produto numa embalagem reciclável em alternativa a comprar um produto similar numa embalagem não reciclável. Além disso, alegam que estariam dispostos a comprar produtos (que agora compram em embalagens menores) em embalagens maiores e com menor 
frequência. Mais da metade dos universitários, afirmaram que comprariam um produto numa embalagem pouco tradicional se isso se traduzisse na criação de menos resíduos sólidos, e ainda, comprariam um produto com uma embalagem menos atrativa se soubessem que todo o plástico e/ou papel desnecessário nesta embalagem pudesse ser eliminado ou reciclado.

No que concerne à hipótese $\mathrm{H3}$, as atitudes positivas em relação ao consumo sustentável têm um impacto positivo na intenção de compra de produtos ecológicos; na escolha entre dois produtos iguais, preferem o que é menos prejudicial tanto à sociedade quanto ao ambiente. Boa parte dos entrevistados já convenceram amigos ou parentes a não comprar produtos que prejudicam o meio ambiente. No que se refere à compra de produtos fabricados ou vendidos por empresas que prejudicam ou desrespeitam o meio ambiente, quase metade se mantiveram neutros, demonstrando que eles não têm percepção clara a respeito do poder do consumidor na preservação ambiental. Ao serem questionados sobre a compra de produtos feitos de papel reciclado, quase metade concordam em comprar produtos feitos em papel reciclado, e, sempre que possível, compram produtos feitos de papel reciclado. Todavia, os universitários não tentam comprar apenas produtos que possam ser reciclados. Este número é preocupante, pois $43 \%$ deles, quantidade bastante significativa, demonstraram neutralidade nesta questão. Ao que tudo indica, esta atitude pode estar ligada ao elevado custo dos produtos reciclados em relação aos não reciclados.

Conclui-se, desta forma, que os jovens estudantes universitários entrevistados, em seu discurso, preocupam-se com a conservação ambiental no momento de decisão do consumo. No entanto, na prática, é possível verificar uma realidade diferente, em especial na valorização da relação custo-benefício em detrimento da relação custo-conservação ambiental e/ou contribuição pessoal com a aquisição de produtos, alimentos e embalagens menos nocivos ao ambiente: “A intenção é boa, mas a práxis é diferente". Tal resultado vai ao encontro do que o Instituto Akatu pôde concluir no ano de 2006 com a pesquisa sobre comportamento consciente, no qual se verificou que existe uma distância entre o falar (valor) e o agir (comportamento).

A observação deste cenário, em uma comunidade acadêmica, pode apontar em direção a uma realidade bastante complicada para um espaço de tantas discussões e de promoção do discurso da conservação ambiental. Porém, há que se levar em conta a falta de cultura de conscientização já enraizada na sociedade, como também, o alto custo dos produtos ecológicos em comparação aos demais produtos tradicionais em oferta no mercado. Para uma geração de poucos recursos, esta situação pode representar uma falta de alternativa econômica em participar dos movimentos em prol do consumo sustentável.

Diante desses resultados faz-se necessário rever as reflexões sobre o consumo sustentável nas discussões providas nas aulas e estudos promovidos na universidade, numa tentativa de ampliar as possibilidades de transformação do comportamento de consumo dos universitários. Por fim, acredita-se que este estudo representa um alerta, ainda que não possa ser considerado como conclusivo devido ao recorte analisado; por isso, recomenda-se a realização de novas pesquisas que possam evidenciar outros fenômenos, contribuindo para a alteração dessa condição.

\section{Referências}

Amorim, B. C., Araújo, A. C., Gonçalves, G. A. C., \& Queiroz, C. T. A. P. (2009). Diagnóstico da Consciência Ambiental dos Gestores: Eco-Atitudes e Consumo Sustentável em Campina Grande /PB-Brasil. Qualit@s Revista Eletrônica, 2(8).

Bedante, G. N. (2004). A influência da consciência ambiental e das atitudes em relação ao consumo sustentável na intenção de compra de produtos ecologicamente embalados. Mestrado Dissertação, Universidade Federal do Rio Grande do Sul, Porto Alegre.

Bedante, G. N., \& Slongo, L. A. (2004). O comportamento de consumo sustentável e suas relações com a consciência ambiental e a intenção de compra de produtos ecologicamente embalados. Paper presented at the Encontro de Marketing - EMA, Atibaia.

Calomarde, J. (2000). Marketing Ecológico. Madrid: Pirámide.

Capelini, M. (2007). Potencialidade e aplicação da prevenção de resíduos de embalagens: abordagem sobre o projeto do produto e o consumo. Doutorado Tese, Universidade de São Paulo, São Paulo.

Cardoso, A. J. M., \& Cairrão, Á. M. C. L. (2009). Os jovens universitários e o consumo sustentável. A sua influência na compra de produtos ecológicos. Biblioteca Digital da Universidade Fernando Pessoa.

Retrieved from https://bdigital.ufp.pt/dspace/bitstream/10284/403/1/124-135_2007.pdf 
Coltro, A. (2006). O comportamento do consumidor consciente como fonte de estímulos de mercado às ações institucionais socioambientais. Paper presented at the Conselho Latino-Americano de Escolas de Administração, Montpellier.

Creswell, J. W. (2010). Projeto de pesquisa: métodos qualitativo, quantitativo e misto (3a ed.). Porto Alegre: Bookman.

Engel, J., Blackwell, R. D., \& Miniard, P. W. (2000). Comportamento do Consumidor (8a ed.). Rio de Janeiro: LTC.

Fraj, E., \& Martinez, E. (2006). Influence of personality on ecological consumer behavior. Journal of consumer behavior, 5(3), 167-182. http://dx.doi.org/10.1002/cb.169

Gade, C. (2000). Psicologia do Consumidor e da Propaganda. São Paulo: Pedagógica Universitária.

Gomes, D. V. (2006). Educação para o consumo ético e sustentável. Revista eletrônica Mestrado de Educação Ambiental, 16(jan./jun.).

Gonçalves-Dias, S. L. F., \& Moura, C. (2007). Consumo Sustentável: Muito Além do Consumo "Verde". Paper presented at the Encontro Nacional dos Programas de Pós-Graduação em Administração, Rio de Janeiro.

Hansen, U., \& Schrader, U. (1997). A modern model of consumption for a sustainable society. Journal of Consumer Policy, 20, 443-468. http://dx.doi.org/10.1023/A:1006842517219

Instituto Akatu. Retrieved 15/01/2010, from http://www.akatu.com.br

Klineberg, S. L., \& Mckeever, M. R. B. (1998). Demographic predictors of environmental concern: It does make a difference how it's measured. Social Science Quarterly, 79(15), 734-753.

Kotler, P. (2000). Administração de Marketing: análise, planejamento, implementação e controle. São Paulo: Prentice Hall.

Lages, N. S., \& Vargas Neto, A. (2002). Mensurando a consciência ecológica do consumidor: um estudo realizado na cidade de Porto Alegre. Paper presented at the Encontro Anual da Associação Nacional de PósGraduação em Administração, Salvador.

Minor, M. S., \& Mowen, J. C. (2003). Comportamento do consumidor. São Paulo: Prentice Hall.

Mittal, J. S. B., \& Newman, B. I. (2001). Comportamento do Cliente: indo além do comportamento do consumidor. . São Paulo: Atlas.

Mourão, É. Guia do consumo consciente Retrieved 10/01/2010, 2010, from

http://www.brde.com.br/asse_midia_consumo.asp

Paavola, J. (2001). Towards Sustainable Consumption: Economics and ethical concerns for the environment in consumer choices. Review of Social Economy, 59(2), 227-248. http://dx.doi.org/10.1080/00346760110036175

Portilho, F. (2005). Consumo sustentável: limites e possibilidades de ambientalização e politização das práticas de consumo. Cadernos EBAPE.BR, 3(Edição Temática), 1-12.

Richardson, R. J. (1989). Pesquisa Social: métodos e técnicas (2ª ed.). São Paulo: Atlas.

Scarpinelli, M., \& Ragassi, G. F. (2003). Marketing verde: ferramenta de gestão ambiental nas empresas. Revista Científica Eletrônica de Ciências Contábeis, 2(1).

Schultz, P. W. (2002). Environmental attitudes and behaviors across cultures. Paper presented at the Online readings in psychology and culture, Washington.

Schwepker, J., C. H., \& Cornwell, T. B. (1991). An examination of ecologically concerned consumers and their intentions to purchase ecologically package products. Journal of Public Policy and Marketing, 10,77 101.

Solomon, M. R. (2002). O comportamento do consumidor: comprando, possuindo e sendo (5a ed.). Porto Alegre: Bookman.

Stiglitz, J., \& Walsh, C. (2003). Introdução à Microeconomia. Rio de Janeiro: Campus.

Straughan, R. D., \& Roberts, J. A. (1999). Environmental segmentation alternatives: a look at green consumer behavior in the new millennium. Journal of Consumer Marketing, 16(6), 558-575.

http://dx.doi.org/10.1108/07363769910297506

Sutherland, A., \& Thompson, B. K. (2003). The Marketer's Guide to Understanding and Reaching Generation $Y$-Kids, Tweens and Teens. New York: McGraw-Hill. 